\title{
AS RELIGIÓES AFRICANAS NO RIO GRANDE DO SUL (BATUQUE)
}

THE AFRICAN RELIGIONS IN RIO GRANDE DO SUL (BATUQUE)

\section{Adalberto Ojuobá Pernambuco ${ }^{1}$}

As Religiooes Africanas chegaram inicialmente ao nosso estado através das entradas - a primeira de que tivemos notícia ocorreu no século XVI, oriunda de Laguna, Santa Catarina, e se dirigindo à cidade de Rio Grande. Após o crescimento da indústria da charqueada, a expansão do comércio negro foi crescendo e, com a chegada de novos escravos, as naçóes africanas foram variando até atingirem as que já foram cultuadas no Rio Grande do Sul: Nagô, Ijexá, Jeje, Oió e Cabinda.

É de se notar que nosso estado jamais recebeu em seu porto principal, o de Rio Grande, um navio negreiro e, por isso, todos os escravos que aqui chegaram foram oriundos dos estados do centro ou do nordeste ou do Uruguai e da Argentina (estes fugidos).

Daí a gama de Naçôes tais como: Nagô, Ijexá, Oió, Jeje e Cabinda aqui cultuadas, notando-se a ausência do Keto que só agora passa a se integrar através da importação do Candomblé da Bahia, tal como ocorreu no Rio de Janeiro e em São Paulo. Este fato, aliás, foi constatado pelo maior estudioso das Religiōes Africanas no Brasil, Roger Bastide, e que, talvez pela ausência da nação a que mais dedicou os seus estudos, tenha considerado o nosso Batuque como uma deturpação daquele Candomblé onde se iniciara.

$\mathrm{Na}$ atualidade, é utilizado apenas o Ijexá, quer pela facilidade do toque como pela ausência de tamboreiros iniciados nos demais Cultos. Raras são as casas que utilizam outro tipo de toque, principalmente os que exigem

1 Breve biografia do autor presente na abertura deste debate, na apresentação de Carvalho, Veras e Emil. 
o uso de oguidavis (varetas) e acreditamos que, talvez, apenas o Pirica de Xangô ainda os use.

A realidade é que, hoje, os nomes das naçôes são apenas rótulos utilizados, talvez para marcar a origem dos fundamentos e náo estes na sua pureza original. Por isso temos visto associações até mesmo impossíveis para designarem os lados das mais variadas casas, tais como: jeje-ijexá, cabinda -oió, oió-jeje e cabinda-ijexá. A explicação é a de que os seus antepassados cultuavam uma nação e os atuais, a tendo trocado também, conservam a designação antiga em respeito aos ancestrais.

Isto ocasionaria, para os que desconhecem o fato, uma verdadeira incógnita, pois naçôes díspares jamais poderiam atuar em conjunto. Assim não poderemos admitir que o Iorubá, que cultua Orixás pudesse invocar, concomitantemente, os Inkices dos bantos ou os voduns dos Jeje. Na verdade, o fato de trabalharem com a naçáo Ijexá esclarece o assunto. Aqui, no Rio Grande do Sul, as casas invocam, todas elas, Orixás, embora apareçam, principalmente nas rezas, os nomes de alguns voduns tais como Badê e Bobô (Bogbo), ambos da família de Kavioso que corresponde ao Xangô dos Iorubas, o primeiro jovem (Aganjú) e o segundo velho (Agodô). Também Bará (corruptela de Legbara), Sapatá (o Xapanam jovem) têm a mesma origem.

Fazendo um apanhado geral e retrospectivo dos cultos adotados no Rio Grande do Sul e suas principais figuras, teremos:

OIÓ - Culto praticamente em extinção restando poucas Casas em atividade. Já foi muito forte e, aos poucos, foi perdendo a sua vitalidade e regredindo para o pequeno número atual. $\mathrm{O}$ último nome da antiguidade que conhecemos foi Tim de Ogum, já falecido, iniciador da Deisa do Ogum, casa ainda em atividade. Além deste vamos encontrar o Antoninho da Oxum e sua filha-de-santo a Moça da Oxum (uma das casas onde o Norton fez a pesquisa para sua tese) como nomes de projeção. Distinguiu-se entre os praticantes do Oió a figura de Fábio da Oxum quer pela beleza e suavidade que o Orixá recebia, quer pelo fato de ter sido um dos raros pais-de-santo que não vivia da Religiáo. Trabalhava como cozinheiro na Prefeitura Municipal de Porto Alegre no Departamento Municipal de Limpeza Urbana, na 
Avenida Azenha onde permanecia das 6 às 15 horas diariamente. Só então se dirigia à sua Casa de Religião quando iniciava o atendimento espiritual. Foi um dos grandes jogadores de búzios que tivemos Outro nome de destaque, este como alabê, foi Donga de Yemanjá.

Distinguia-se esta Nação das demais principalmente pela ordem das rezas - eram chamados primeiro os Orixás masculinos e logo a seguir os femininos encerrando-se as rezas com Yansã (Oiá), Xangô e finalmente Oxalá. O destaque para os dois Orixás é decorrente do fato de serem o Rei e a Rainha de Oió. Em algumas Casas onde assisti toques, estes dois orixás eram inclusive invocados após Oxalá. Outro ponto de distinção é a realização de uma obrigação, no encerramento da festa, com as cabeças dos animais já em decomposição que os Orixás no mundo conduziam nas bocas de seus filhos incorporados. Diziam alguns dos mais antigos que os ocutás eram enterrados ao invés de serem colocados em prateleiras. As que frequentamos não mantinham esta tradiçáo, aliás fruto dos tempos da escravidão em que todas as obrigaçóes eram colocadas sob a terra.

Esta nação veio para Porto Alegre de Rio Grande e situou-se, em princípio, na Azenha, de onde se deslocou para o Areal da Baronesa e dali para o Mont'Serrat onde se estabeleceram as principais casas de culto.

IJEXÁ - Nação que predomina hoje no Rio Grande do Sul inobstante sejam usados outros rótulos para as mais variadas Casas. Os toques são executados e os Orixás invocados são todos Iorubas. Curioso, no caso, é que dos dois maiores ramos predominantes na Bahia, o Keto foi o único a não vir para o nosso Estado.

As maiores casas de fundamento Jeje passaram para nação Ijexá. Podemos citar como exemplo a raiz do Manoelzinho do Xapaná que se iniciou na Cabinda e posteriormente no Jeje, tendo a sua descendência se desviado para o Ijexá, conquanto se digam Jeje-Ijexá. Neste caso, Ester da Yemanjá (outra casa pesquisada pelo Norton e que frequentávamos) e Diva da Yemanjá (também de nosso relacionamento) de Viamão. Da descendência da Ester temos ainda a mais antiga de suas filhas, Santinha do Ogum, com seus filhos e netos, Landa da Yemanjá e Marcos da Oxum. Os demais antigos faleceram. 
Outra raiz que também se desviou foi a do Tati do Bará, também iniciado na Cabinda passando diretamente para o Ijexá. Filho dele foi Eliseu do Ogum cuja descendência vem deixando decair o seu nome. Posso dizê-lo tranquilamente pois foi o nosso iniciador no Culto Africano. Restam de sua descendência, segundo o que sabemos, as casas de suas filhas gêmeas (de criação) e de sua filha-de-santo, Haydé.

$\mathrm{O}$ curioso destes dois pais-de-santo foi a luta espiritual em que se envolveram a Ester e o Eliseu e que culminou com o falecimento dos dois velhos, um em seguida do outro. Esta inimizade perdurou durante longos anos e quando nos iniciamos no Eliseu ainda restavam fortes resquícios da mesma tendo nos condicionado a nossa iniciaçáo ao direito de frequentar as duas casas. Tivemos a felicidade de conseguir, antes do desencarne da Ester, que o Eliseu participasse de um toque na sua casa.

Um dos principais fundamentos desta Naçáo se denominava a "Mesa dos Prontos" e era realizado ao início da festa principal da Casa. Consistia em se colocar no chão uma toalha e, sobre ela, vários pratos, cada um com a comida principal de cada Orixá. A seguir sentavam-se em volta da mesa os participantes que já tinha feito todas as suas obrigaçóes tendo à cabeceira o dirigente do Cento. A seguir os tamboreiros puxavam uma reza para cada Orixá e o prato do correspondente àquela reza percorria toda a volta até retornar ao ponto de origem. De cada prato devia o participante comer uma pequena porção. A pipoca do Bará abria e a canjica branca de Oxalá encerrava a mesa que era levantada ritualisticamente dando-se início ao Toque. A última Mesa de Prontos a que assistimos foi em Santa Maia na casa do Negro do Xangô e da Helena da Oxum (filhos-de-santo da Ester). Sabemos, contudo, de fonte segura, que a Casa da Dila da Obá ainda promove esse ritual mantendo, assim, uma tradição das mais preciosas.

JEJE - Foi, durante muito tempo, a Nação que predominou no Rio Grande do Sul em que pese o fato de jamais termos ouvido falar em voduns a exemplo dos cultuados em São Luís do Maranháo. Sempre ouvimos dos que se dizem Jeje puros falar e invocar os Orixás Nagô. Isto é um fator que 
deverá ser objeto de estudos por um pesquisador disposto a despender um tempo bastante prolongado e uma paciência ainda maior.

Dada a complexidade dos seus toques, a morosidade dos mesmos e a dificuldade na preparação dos tamboreiros que, inclusive, deviam usar os oguidavis, de difícil manejo, foram adotando as rezas do Ijexá que hoje predominam mesmo entre as que se dizem de Jeje.

Figuras exponenciais desta Nação foram Paulino do Oxalá Efan que reiniciou no Jeje ao Manoelzinho do Xapanã e Tato do Barà, oriundos da Cabinda e que por longo tempo dominaram os meios religiosos de Porto Alegre. Também seu filho foi Joãozinho do Barà aquela figura quase lendária e que fez com que o Batuque do Rio Grande do Sul atravessasse as fronteiras penetrando nos países do Mercosul onde sua figura é até hoje venerada por seus filhos e netos-de-santo. Levada por sua mãe ingressou, principalmente, na Argentina, a Ester que havia sido deixada a seu cuidado pelo Manoelzinho. Com o desencarne de Ester, boa parte dos seus filhos argentinos passaram para a mão da sua filha a Santinha do Ogum.

Outro pai-de-santo que desfrutou de grande conceito em Porto Alegre, principalmente pelos profundos fundamentos de que era portador, foi Idalino do Ogum que desencarnou com a idade avançada de 104 anos. Idalino morava no Mato Sampaio, um dos bairros mais perigosos desta capital, e apenas aqueles que o buscavam eram respeitados pelos marginais que ali pululavam e que tinham por ele imenso respeito.

Quatro coisas distinguiram Idalino como sacerdote da religião: o fato de ter nascido e morrido pobre; a maneira peculiar de jogar os búzios, ou seja, promovendo a todas as jogadas para depois dar o resultado como um todo; o fato de, a exemplo dos Jejes puros, consultar Ifá antes de tomar uma decisão e ser o único babalorixá possuidor do axé de faca de boi (seria mais correto dizermos de touro pois o animal tinha de ser inteiro). Muitos se dizem possuidores de tal azé mas a realidade é que matam o boi e não touro. Inclusive conhecemos mulheres que se ostentam como tal sem atentarem para o fato que este axé é vedado ao sexo feminino. 
Outra figura, esta legendária, foi o famoso Príncipe Custódio, herdeiro do trono de Benin e que residiu, até sua morte, em Porto Alegre após haver transitado por Santos, Bagé e Rio Grande.

Exilado de sua terra natal e separado de sua família, como acontecia no sistema colonialista inglês, Custódio recebia uma pensão vitalícia do Império, quantia que lhe era paga em libras esterlinas ouro pelo Banco de Londres, através de seu correspondente no Brasil, o Banco do Brasil e que cessou após seu falecimento.

Como todo membro da família real, era iniciado na Religião Africana (no caso a da Nação Jeje) e trouxe o seu assentamento construindo o seu peji no haras que manteve onde hoje temos o bairro do Menino Deus e onde cultuava os seus Voduns dentro de sua tradição religiosa. É certo que jamais iniciou pessoa alguma dentro da Religião, já que não poderia colocar sua mão na cabeça de nenhum que não possuísse título de nobreza e que não fosse africano puro ou descendente de africanos nascidos no Brasil. Obviamente jamais colocaria a máo na cabeça de um branco e, menos ainda, na de um crioulo que na África é considerado um traidor da pureza da raça.

Convivemos por muitos anos com uma professora da UFRGS, recentemente falecida, cujo pai vizinhou por muitos anos com o Príncipe e esta nos contou das visitas que ele fazia a seu pai e da impressáo que lhe causava aquela figura de elevada estatura, com uma voz extremadamente possante e sempre portando um charuto cubano nas mãos. As empregadas de sua casa lhe contavam, que o mesmo mantinha um harém, de cerca de 30 mulheres, todas negras ou mulatas, a maioria menor de idade e algumas até acorrentadas às paredes porque eram fujonas. Daí nasceram vários filhos, alguns conhecidos outros desconhecidos, mas que, na realidade, jamais poderiam usar títulos de nobreza eis que naturais e não legítimos.

Com o falecimento do Príncipe surgiram várias pessoas que passaram a se apresentar como seus filhos-de-santo o que nos faz lembrar o caso da Menininha quando, após sua morte, surgiram tantos filhos que um pesquisador, se náo me falha a memória, Verger, disse que se ela tivesse aprontado todos os que assim se intitulavam, estaria trabalhando até hoje em espírito. 
Inclusive o entáo governador do estado Borges de Medeiros, foi dado como seu filho o que não corresponde à realidade. Borges era positivista e como tal permaneceu em vida. A professora a que aludimos nos disse que por várias vezes ele esteve na casa do Príncipe para fazer trabalhos que, segundo o seu pai, visavam mantê-lo no poder. É evidente que a contribuição da presença do Príncipe, em nosso meio, pouco ou nada acresceu em favor da Religiáo Africana. O certo é que durante sua vida dedicou-se, isto sim, ao seu esporte predileto: o turfe.

CABINDA - Esta é uma nação de culto tão estranho como o Jeje e isto porque conquanto seja uma naçáo banto, jamais ouvimos falar sobre Inkices. O Orixá iorubano sempre foi cultuado. A figura mais marcante do culto chamava-se Waldemar do Xangô (porque não Zaze que é inkice?) Kamucá e, segundo afirmam, quem trouxe o culto do cabinda para o Rio Grande do Sul foi um negro africano que era conhecido por Gululu e de suas mãos devem ter saído o Waldemar, a sua filha Palmira, a Madalena, que foi máe do Romário de Oxalá e o Henrique da Oxum. Hoje todos falecidos. Restam apenas os filhos do Henrique e os do Cleon do Oxalá que se intitula o único herdeiro do ritual, um ritual que, como vimos, de sua origem mantém apenas o rótulo: o conteúdo é todo eke Ijexá. É outra naçáo que mereceria uma profunda pesquisa.

NAGÔ - Esta é uma nação que, tendo sido a origem do Culto no Rio Grande do Sul, hoje está praticamente extinta restando pouquíssimas Casas. Em Porto Alegre apenas duas correntes restam. A do Jader e a do Múcio (este falecido) e ambas oriundas de Pelotas. O primeiro foi iniciado por Lúcia de Ibejis, de origem africana, e trouxe a sua nação para Porto Alegre onde abriu CEU Nova Era, uma casa que cultua a Umbanda e a Naçáo trabalhando separadamente com ambas as linhas. $\mathrm{O}$ segundo pertence à corrente divergente, comandada em Pelotas por Paulito de Castro e Silva, a qual pertenceram José Coelho (de quem Múcio era filho-de-santo), Ibrahim Antonio Trepto e Emanuel Zespo, este último conhecido por um livro que escreveu sobre Umbanda, Codificação da Lei de Umbanda. 
A diferença entre as duas correntes é bastante acentuada parecendo-nos que o Jader mantém uma tradição mais pura com a sua casa nos fazendo lembrar o que narra Beatriz Góes Dantas em seu livro Vovó Nagô e Papai Branco, o ritual nagô das Alagoas. A chegada dos Orixás se faz como no Candomblé (linha por linha, trabalhando e desincorporando) e a matança é procedida com o animal no chão e não suspenso. Jader pratica um ritual africano fechado e raros são os convidados de fora que participam do mesmo. Até os seus médiuns de Umbanda comparecem em reduzido número. É uma casa que merecia um estudo a fim de situarmos ali, talvez, a semente do culto africano plantada pelos escravos das charqueadas, desde a sua origem em Rio Grande, cidade da qual não conseguimos obter nenhuma informação.

\section{UMBANDA GAÚCHA}

A Umbanda nasceu, no nosso estado em 1926 trazida pelas mãos de OTACÍLIO CHARÃO, no distrito de São José do Norte, município de Rio Grande. O seu Centro se denominava Reino de São Jorge. O seu uniforme de trabalho era um macacão de operário, de cor branca com uma cinta onde se podiam ver pembas de várias cores e uma ponteira de aço.

Otacílio recebida o Caboclo Vira Mundo e o Preto Velho Girassol, entidades espirituais que dirigiam a Casa. Além da perseguição policial a uma doutrina que era encarada como feitiçaria, ele teve que enfrentar a reação contrária, não apenas dos kardecistas que não concordavam com a ritualística, como também a dos africanistas que náo concordavam com o náo uso do sangue animal. A Casa usava uma magia estranha utilizando-se, além da seiva de vegetais, flores, frutos, perfumes. Ademais, os seus trabalhos eram feitos em cachoeiras, pedreiras, rios, matas, cruzeiros e no mar, inclusive os dos aprontamentos dos médiuns.

O cháo batido da terreira era sempre coberto de folhas e os trabalhos de incorporação realizados ao som de palmas, sem os tradicionais atabaques 
dos Cultos afro e utilizando a defumação, o fumo e as bebidas também vedadas nas casas de fundamento africano.

De São José do Norte a doutrina atingiu Rio Grande, Pelotas e outras localidades vizinhas até que, em 1932, o Capitão da Marinha LAUDELINO DE SOUZA GOMES fundou, nesta Capital, o primeiro Centro de Umbanda e que se denominou CONGREGAÇÃO ESPÍRITA DOS FRANCISCANOS DE UMBANDA, trabalhando na Linha de Semiromba, e cujos remanescentes ainda trabalham na Avenida Ipiranga.

Estes dois pioneiros enfrentaram o auge da perseguição policial, especialmente na época do Geral Daltro Filho quando a Brigada Militar invadia os Centos Espíritas e as Casas de Nação a cavalo destruindo o que encontrava pela frente.

É curioso notar que tanto Otacílio como Laudelino estiveram na África por longos anos mas foram incumbidos pelo Astral de plantarem no solo gaúcho a semente da nossa Umbanda. Ainda hoje, nos Franciscanos de Umbanda, podemos encontrar pelo menos um tambor trazido pelo Laudelino, tipicamente bantu, e que, segundo sua sucessora, a irmã Núbia, poucas vezes foi utilizado em trabalhos.

Existia, nas antigas Casas de Umbanda, um local mágico denominado pelos guias de ARUANDA onde se processavam os trabalhos de desobsessão, descarrego e desmancho. Pudemos ver um em funcionamento no CEU Cacique de Humaitá, em Viamão, dirigido à época pelo saudoso irmão Norberto de Oliveira, ele foi o precursor da Umbanda no município de Viamão ajudando na fundação da quase totalidade das primeiras casas que ali ainda hoje funcionam.

Recebido em: 27/10/2018

Aprovado em: 27/10/2018 
